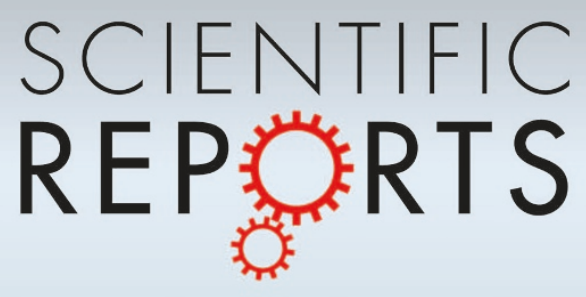

OPEN

SUBJECT AREAS:

CHEMICAL SYNTHESIS

METHODOLOGY

BIOMEDICAL ENGINEERING

FLUORESCENCE IMAGING

Received

23 October 2012

Accepted

11 December 2012

Published

28 January 2013

Correspondence and requests for materials should be addressed to B.L. (cheliub@nus.edu.

sg) or B.Z.T.

(tangbenz@ust.hk)

* These authors contributed equally to this work.

\title{
Photostable fluorescent organic dots with aggregation-induced emission (AIE dots) for noninvasive long-term cell tracing
}

\author{
Kai Li1,2*, Wei Qin ${ }^{3 *}$, Dan Ding², Nikodem Tomczak', Junlong Geng², Rongrong Liu' , Jianzhao Liu³, \\ Xinhai Zhang', Hongwei Liu', Bin Liu',2 \& Ben Zhong Tang',3,4
}

${ }^{1}$ Institute of Materials Research and Engineering, 3, Research Link, Singapore $117602,{ }^{2}$ Department of Chemical and Biomolecular Engineering, National University of Singapore, 4 Engineering Drive 4, Singapore 117576, ${ }^{3}$ Department of Chemistry, Division of Biomedical Engineering, Institute for Advanced Study, State Key Laboratory of Molecular Neuroscience, and Institute of Molecular Functional Materials, The Hong Kong University of Science \& Technology, Clear Water Bay, Kowloon, Hong Kong, China, ${ }^{4}$ SCUT-HKUST Joint Research Laboratory, Guangdong Innovative Research Team, State Key Laboratory of Luminescent Materials and Devices, South China University of Technology, Guangzhou, China, 510640.

Long-term noninvasive cell tracing by fluorescent probes is of great importance to life science and biomedical engineering. For example, understanding genesis, development, invasion and metastasis of cancerous cells and monitoring tissue regeneration after stem cell transplantation require continual tracing of the biological processes by cytocompatible fluorescent probes over a long period of time. In this work, we successfully developed organic far-red/near-infrared dots with aggregation-induced emission (AIE dots) and demonstrated their utilities as long-term cell trackers. The high emission efficiency, large absorptivity, excellent biocompatibility, and strong photobleaching resistance of the AIE dots functionalized by cell penetrating peptides derived from transactivator of transcription proteins ensured outstanding long-term noninvasive in vitro and in vivo cell tracing. The organic AIE dots outperform their counterparts of inorganic quantum dots, opening a new avenue in the development of fluorescent probes for following biological processes such as carcinogenesis.

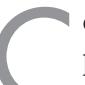

ontinuous in vivo cell tracing over a long period of time can offer valuable information on cellular processes and biomedicinal therapies ${ }^{1-6}$. Among the bioimaging techniques such as positron emission tomography ${ }^{7}$, single photon emission computing tomography ${ }^{8}$, and magnetic resonance imaging ${ }^{9}$, fluorescence technique is advantageous, in terms of more varieties of biocompatible, inexpensive and readily available imaging reagents and more maneuverable instruments that can provide images with higher resolutions at the cellular level ${ }^{10,11}$. To efficiently trace living cells in a noninvasive and real-time manner, researchers have devoted much effort to develop new fluorescent probes. Green fluorescent protein (GFP) and its variants have been adopted for genetic cell tagging to achieve long-term cell tracing ${ }^{12,13}$. However, they suffer from a number of drawbacks, such as inherent susceptibility to proteolytic enzymes, severe spectral overlap with biosubstrate autofluorescence, and poor photostability ${ }^{14-16}$. Moreover, recent studies reveal that fluorescent protein transfection can disrupt normal cell function and the tagging is often low in efficiency, which limit the scope of practical applications of the GFP-based probes ${ }^{17}$.

Besides GFP, inorganic semiconductor quantum dots (QDs) have also been used as cell labeling reagents. QDs are highly emissive and photostable and can label living cells by facile procedures in high efficiency ${ }^{18-21}$. The internalized QD probes have been reported to stay in the cytoplasm and transfer to daughter cells up to $\sim 6$ generations due to their excellent retention in living cells without leaking during proliferation ${ }^{22}$. Their heavy metal cores, however, can be oxidized in the complex biological environment and their interactions with the intracellular thiols can degrade QD surface encapsulating layers, leading to undesired cytotoxicity, serious aggregation, and unstable fluorescence signals ${ }^{23}$. In comparison to inorganic QDs, organic molecules are richer in variety and more compatible with living cells ${ }^{24}$. Unfortunately, isolated organic fluorophores are susceptible to photobleaching and easy to leak out from cytoplasm to media, which greatly compromise their performance ${ }^{25-27}$. It is thus envisaged that fabrication of fluorophore nanoparticles may generate organic dots that share similar optical features and cellular retention time but show superior cytocompatibility and fluorescence stability to the QDs. Realization of this idea requires organic fluorophores with high fluorescence efficiency in the aggregate 
state, which is challenging because light emissions of conventional organic fluorophores are often weakened or annihilated when they are aggregated, a general phenomenon notoriously known as aggregation-caused quenching (ACQ) ${ }^{28}$.

We have discovered an "abnormal" phenomenon of aggregationinduced emission (AIE) that is exactly opposite to the abovementioned ACQ effect ${ }^{29}$. Propeller-shaped AIE fluorogens are non-emissive in solutions but become highly fluorescent upon aggregate formation because the restriction of the intramolecular rotations (RIR) due to the physical constraint in the aggregates opens radiative decay channel ${ }^{30}$. The AIE effect makes the fluorogens ideal candidate materials for the preparation of fluorescent nanoparticles ${ }^{31-33}$. We have previously shown that AIE nanoparticles with stable fluorescent signals and good cellular retention can trace HeLa cells for $\sim 4$ generations in vitro ${ }^{34}$. The AIE nanoparticles, however, emitted a green light when excited by an ultraviolet (UV) light. For in vivo cell tracing, it is desirable to shift the excitation and emission to longer wavelengths, ideally to far-red/near-infrared (FR/NIR) region, which will avoid photodamage caused by the UV excitation, enable deep tissue penetration, and circumvent the spectral overlap with biosubstrate autofluorescence ${ }^{35}$.

Development of efficient FR/NIR emitters in the aggregate state is particularly demanding because conventional FR/NIR emitters are normally large disc-shaped planar molecules, which tend to aggregate through $\pi-\pi$ stacking interaction, thus suffering from severe ACQ effect. In this work, we designed an FR/NIR fluorogen named 2,3-bis[4-(diphenylamino)phenyl]fumaronitrile (Fig. 1a), which is abbreviated as TPAFN as it is an adduct of triphenylamine (TPA) and fumaronitrile (FN). Thanks to its propeller-like nonplanar structure, the fluorogen is AIE active. We further attached tetraphenylethene (TPE), an iconic AIE unit, to TPAFN to produce 2,3-bis(4(phenyl(4-(1,2,2-triphenylvinyl)phenyl)amino)phenyl)fumaronitrile (Fig. 1b), an adduct of TPE and TPAFN (thus the abbreviation of TPETPAFN). The molecular fusion of the two types of AIE units $(\mathrm{TPE}+\mathrm{TPAFN})$ resulted in the generation of a new fluorogen with extended electronic conjugation, long absorption wavelength and large molar absorptivity (Fig 1c). Its nanoaggregates exhibit strong AIE activity, bright red emission, high fluorescence quantum efficiency, superb cytocompatibility, and good resistance to photobleaching. These remarkable attributes offer the AIE dots a promising prospect as a long-term cell tracer.

In this contribution, we report the synthesis of AIE-active TPETPAFN and the fabrication of its FR/NIR AIE dots for in vitro and in vivo long-term cell tracing applications. A mixture of lipidpoly(ethylene glycol) (PEG) and lipid-PEG- $\mathrm{NH}_{2}$ was chosen as the encapsulation matrix to endow the AIE dots with biocompatibility and surface functionality. Bioconjugation of the AIE dots with cell penetrating peptide derived from HIV-1 transactivator of transcription (Tat) protein, yielded Tat-AIE dots with high cellular internalization efficiency ${ }^{36}$. The performances of the Tat-AIE dots in the in vitro and in vivo studies were compared with those of commercially available QDs of Qtracker ${ }^{\circledR} 655$ under similar experimental conditions. It was found that the Tat-AIE dots could trace MCF-7 cells for 10-12 generations in vitro and C6 cells for 21 days in vivo. One- and two-photon excited ex vivo tumor images were taken to highlight the deep tissue imaging ability of the Tat-AIE dots. This is the first successful demonstration of the AIE dots for in vitro and in vivo long-term cell tracing, which offers new opportunities and bright prospects in the areas of cancer research, real-time monitoring of stem cell transplantation and other cell-based therapies.

\section{Results}

Synthesis and optical properties of AIE fluorogens. TPETPAFN and TPAFN were synthesized according to the synthetic routes shown in Supplementary Fig. S1. The key intermediate bis (4-bromophenyl) fumaronitrile (2) was prepared from 4-bromophenylacetonitrile (1) in a basic medium in $86 \%$ yield. Reaction of 2 with aryl amine 7 or 8 in the presence of $\mathrm{Pd}(\mathrm{OAc})_{2}$ under basic condition led to TPETPAFN (9) or TPAFN (10) in $61 \%$ and $50 \%$ yields, respectively. The purified products were characterized by standard spectroscopic techniques, and the data indicate their right chemical structures with high purity. Detailed data are shown in the Methods and Supplementary a

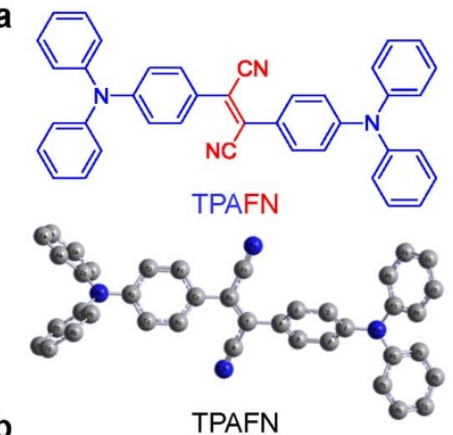

b

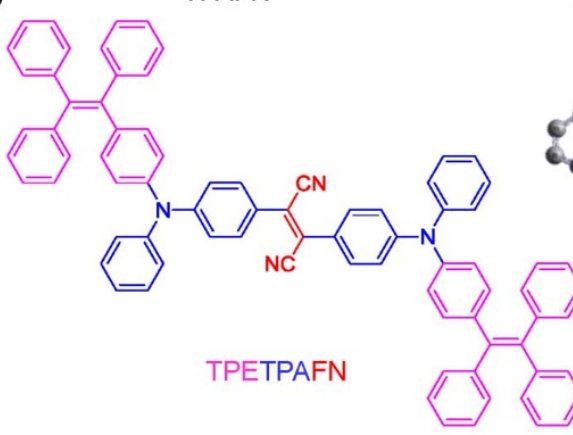

C
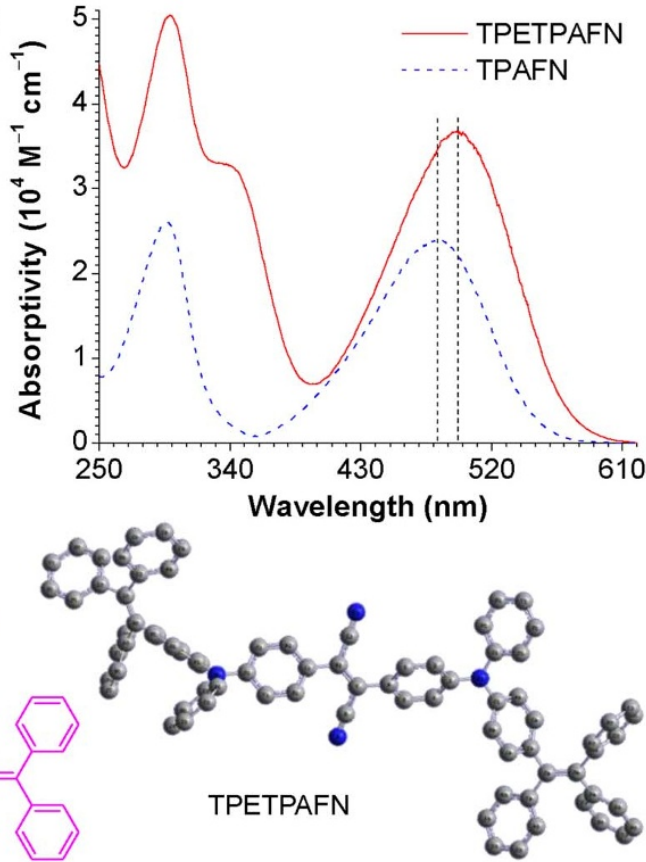

Figure 1 Structures and absorptivities of the luminogens used in this study. (a and b) Chemical structures and molecular geometries of (a) TPAFN [an adduct of triphenylamine (TPA) and fumaronitrile (FN)] and (b) TPETPAFN [an adduct of tetraphenylethene (TPE) and TPAFN]; the molecular geometries were optimized by the DFT calculations using B3LYP/6-31G(d) basis set in Gaussian 03 program; hydrogen atoms were omitted for clarity. (c) Absorption spectra of TPAFN and TPETPAFN in tetrahydrofuran (THF) solutions with a concentration $(c)$ of $1 \mu \mathrm{M}$. 
Methods and the examples of spectra are shown as Supplementary Figs S2-S5.

TPETPAFN and TPAFN have donor-acceptor (D-A) structures, which contain elementary units of electron-donating triphenylamines and electron-accepting fumaronitrile (FN). TPETPAFN differs from TPAFN by having one of the phenyl rings in triphenylamine replaced by TPE. The absorption spectra of TPETPAFN and TPAFN in tetrahydrofuran (THF) are peaked at $\sim 497$ and $\sim 484 \mathrm{~nm}$, respectively, indicative of a longer conjugation length of the former (Fig. 1). The molar absorptivity of TPETPAFN $(3.68 \times$ $10^{4} \mathrm{M}^{-1} \mathrm{~cm}^{-1}$ ) is $\sim 1.5$-fold larger than that of TPAFN (Supplementary Table S1). Density functional theory (DFT) calculations of the TPAFN and TPETPAFN were carried out to understand their geometries and electronic structures at the molecular level. The optimized geometries of TPAFN and TPETPAFN are shown in Figs 1a and $1 \mathrm{~b}$, respectively. Both molecules adopt twisted conformations along the backbone. The torsion angles between the central FN plane ( $\mathrm{C}-\mathrm{C}$ double bond and two CNs almost in the same plane) and their adjacent phenyl rings are $\sim 35^{\circ}$ for both molecules (Supplementary Tables S2 and S3). The dihedral angles between any two phenyl rings of the triphenylamine are in the range from $64^{\circ}$ to $76^{\circ}$. In the TPE part of TPETPAFN, the dihedral angles between any phenyl ring and the central double bound are about $50^{\circ}$ (Supplementary Table S3). Such propeller-like, nonplanar conformations of these two molecules, especially for TPETPAFN, would significantly hamper the $\pi-\pi$ stacking interactions in the aggregate state. In terms of the electronic structures, the lowest unoccupied molecular orbitals (LUMOs) of both molecules are dominated by the orbitals from the 2,3-diphenylfumaronitrile core, while the electron clouds of the highest occupied molecular orbitals (HOMOs) are extended to triphenylamine and even to TPE parts (Supplementary Fig. S6). The HOMO-LUMO distribution indicates that the AIE molecules possess an intrinsic intramolecular charge transfer (ICT) character.

The photoluminescence (PL) spectra of TPAFN and TPETPAFN were studied in THF/water mixtures with different water fractions $\left(f_{\mathrm{w}}\right)$, which enabled fine-tuning of the solvent polarity and the extent of solute aggregation (Fig. 2). The pure THF solution of TPAFN shows weak red fluorescence with an emission maximum at $652 \mathrm{~nm}$. With gradual addition of water into THF $\left(f_{\mathrm{w}} \leq 70 \mathrm{vol} \%\right)$, the emission of TPAFN is weakened and is bathochromically shifted from 652 to $665 \mathrm{~nm}$, possibly due to the increase in solvent polarity and hence the transformation to the twisted intramolecular charge transfer (TICT) state. The TICT phenomenon is often observed in DA fluorophores that are featured with red-shifted emission and decreased emission intensity with increasing solvent polarity. When more water $\left(f_{\mathrm{w}}>70 \mathrm{vol} \%\right)$ is added, TPAFN molecules cluster into nanoaggregates due to the poor solubility and the emission is dramatically enhanced with an increase in $f_{\mathrm{w}}$, showing an obvious AIE effect. In addition, the emission maximum is shifted back to $655 \mathrm{~nm}$ which is similar to that in pure THF. The emission intensity at $f_{\mathrm{w}}=90 \mathrm{vol} \%$ is 12 -fold higher than that in pure THF solution.

In a typical AIE luminogen (e.g., TPE), intramolecular rotations play a crucial role to populate the nonradiative decay channels (e.g., internal conversion) for the excited states and thus effectively quench the light emission ${ }^{37,38}$. Bearing two extra TPE units to TPAFN, TPETPAFN has more freely rotated rotors and is expected to have
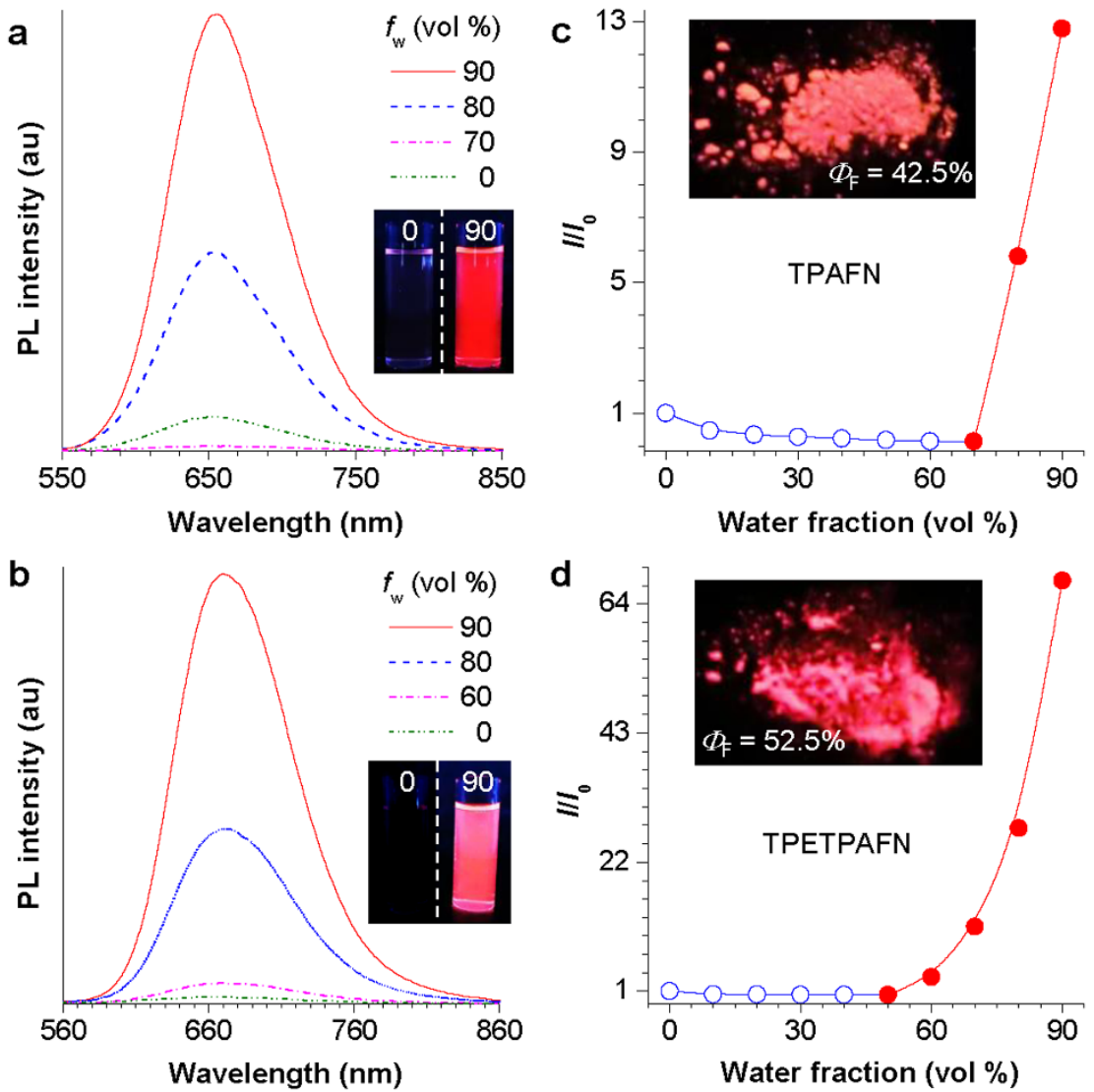

Figure 2 Aggregation-induced emission (AIE). (a and b) Photoluminescence (PL) spectra of (a) TPAFN and (b) TPETPAFN in THF/water mixtures with different water fractions $\left(f_{\mathrm{w}}\right) ; c=1 \mu \mathrm{M}$; excitation wavelength $\left(\lambda_{\text {ex }}\right)$ : (a) $485 \mathrm{~nm}$, (b) $500 \mathrm{~nm}$. Insets: fluorescent photographs of (a) TPAFN and (b) TPETPAFN in THF $\left(f_{\mathrm{w}}=0 \%\right.$ ) and a THF/water mixture with $f_{\mathrm{w}}=90 \%$. (c and d) Variations in $I / I_{0}$ of $(\mathrm{c})$ TPAFN and (d) TPETPAFN with $f_{\mathrm{w}} . I_{0}$ and $I$ are the PL intensities in THF $\left(f_{\mathrm{w}}=0\right)$ and a THF/water mixture with a specific $f_{\mathrm{w}}$, respectively. Insets: fluorescent photographs of powders of (c) TPAFN and (d) TPETPAFN; $\Phi_{\mathrm{F}}=$ fluorescence quantum yield. 
a more pronounced AIE effect. As shown in Fig. 2b, TPETPAFN is almost nonluminescent in THF under a hand-held UV lamp. The magnified PL spectrum reveals an emission peak located at $660 \mathrm{~nm}$, which is $8 \mathrm{~nm}$ red-shifted from that of TPAFN. With gradual addition of water into THF at $f_{\mathrm{w}} \leq 50 \mathrm{vol} \%$, the emission keeps silent and is almost unchanged in profile. At $f_{\mathrm{w}}>50 \mathrm{vol} \%$, the light emission is turned on and exponentially intensified with $f_{\mathrm{w}}$. At $f_{\mathrm{w}}=90 \mathrm{vol} \%$, a 70 -fold enhancement of emission has been observed as compared to that in THF. These data demonstrate that TPETPAFN is a luminogen having a stronger AIE effect but a negligible TICT effect relative to TPAFN. The fluorescence quantum yield $\left(\Phi_{\mathrm{F}}\right)$ gives a quantitative measure of the AIE effect. The $\Phi_{\mathrm{F}, \mathrm{s}}$ 's of TPAFN and TPETPAFN in THF are as low as 2.32 and $0.59 \%$, while their $\Phi_{\mathrm{F}, \mathrm{f}}$ 's in solid state reach 42.5 and $52.5 \%$, respectively (Supplementary Table S1). After covalent integration of TPE, TPETPAFN enjoys $\sim 24 \%$ enhancement in solid state emission efficiency compared to its parent TPAFN. Their corresponding AIE factors defined by $\Phi_{\mathrm{F}, \mathrm{f}} / \Phi_{\mathrm{F}, \mathrm{s}}$ are $\sim 18$ and $\sim 89$, indicating larger AIE effect of TPETPAFN. Meanwhile, no obvious PL spectral shifts were observed from solution to solid state, ruling out the possibility of $\pi-\pi$ stacking interactions involved in the aggregate state. As a result, TPETPAFN is more suitable to serve as a fluorophore for constructing AIE dots to satisfy sophisticated bioimaging applications.

Preparation and characterization of Tat-AIE dots. The AIE dots with surface amine groups were synthesized through a modified nanoprecipitation method (Fig. 3a) ${ }^{39}$. 1,2-Distearoyl-sn-glycero-3phosphoethanolamine- $N$-[methoxy(polyethylene glycol)-2000] (DSPE$\left.\mathrm{PEG}_{2000}\right)$ and its amine end-capped DSPE-PEG $2000-\mathrm{NH}_{2}$ were used to encapsulate TPETPAFN to afford AIE dots with surface amine groups. The synthesis starts with the preparation of a THF solution containing TPETPAFN (1 mg), DSPE-PEG $2000(0.75 \mathrm{mg})$ and DSPE-PEG $2000-\mathrm{NH}_{2}(0.75 \mathrm{mg})$. Upon mixing the THF solution with water under continuous sonication, the hydrophobic lipid segments tend to be embedded in aggregated hydrophobic TPETPAFN core while the hydrophilic PEG chains extend into the aqueous phase to render the dots with abundant surface amine groups. After THF removal, the water suspension of AIE dots was reacted with cell penetrating peptide HIV-1 Tat through carbodiimide-mediated coupling to afford Tat-AIE dots ${ }^{40}$. No obvious precipitation from the Tat-AIE dots suspension was observed after being stored at $4^{\circ} \mathrm{C}$ for 3 months, indicating excellent colloidal stability.

The sizes of Tat-AIE dots were investigated by laser light scattering (LLS), suggesting that the volume average hydrodynamic diameter is $32 \pm 2 \mathrm{~nm}$. Fig. $3 \mathrm{~b}$ shows the size distribution of Tat-AIE dots in water. The morphology of Tat-AIE dots was further investigated using high-resolution transmission electron microscopy (HRTEM), indicating that they are in spherical shape with an average size of $29 \pm 3 \mathrm{~nm}$. The dark dots are due to the high electron density of TPETPAFN. As shown in Fig. 3c, Tat-AIE dots have an intense absorption peak at $511 \mathrm{~nm}$, which matches well with the confocal laser excitation at $514 \mathrm{~nm}$. The emission maximum appears at

a

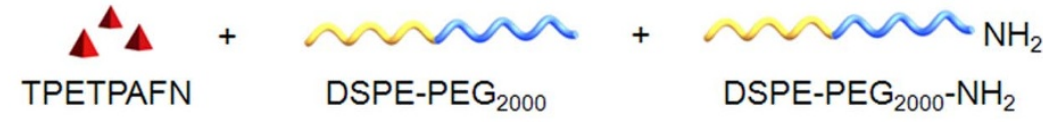

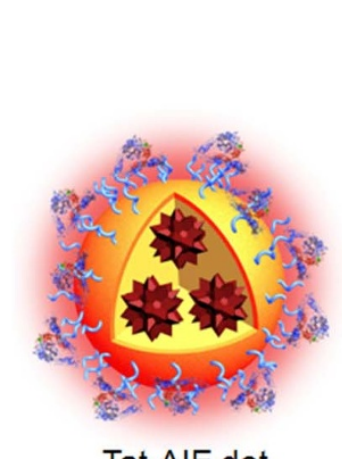

Tat-AIE dot

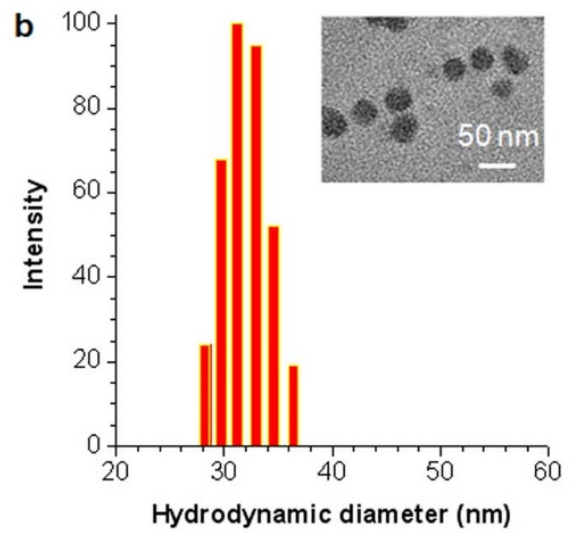

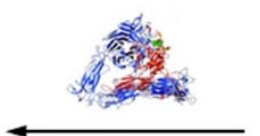

ii

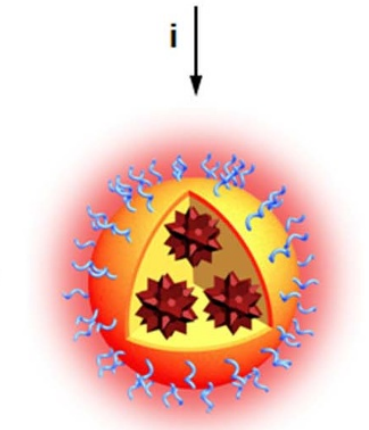

AIE dot

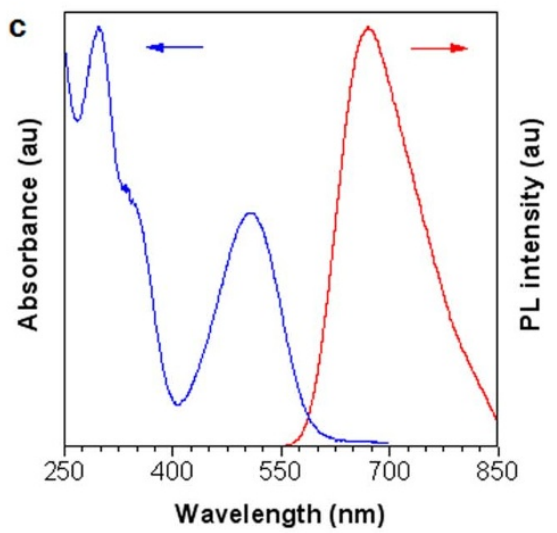

Figure 3 Fabrication and characterization of organic Tat-AIE dots. (a) Fabrication of Tat-AIE dots: i) Addition of a THF solution of TPETPAFN, 1,2-distearoyl-sn-glycero-3-phosphoethanolamine- $N$-[methoxy(polyethylene glycol)-2000] (DSPE-PEG 2000 ) and its derivative end-capped by amino group (DSPE-PEG $2000-\mathrm{NH}_{2}$ ) into water under sonication affords amine-decorated core-shell organic dots with AIE characteristics (AIE dots); ii) Coupling of the amine-functionalized AIE dots with cell penetrating peptide yields Tat-AIE dots. (b) Particle size distribution and morphological structure of Tat-AIE dots studied by laser light scattering (LLS) and (inset) high-resolution transmission electron microscopy (HR-TEM). (c) Absorption and emission spectra of Tat-AIE dots suspended in water; $\lambda_{\mathrm{ex}}=510 \mathrm{~nm}$. 
$671 \mathrm{~nm}$ with an emission tail extending to $900 \mathrm{~nm}$, which is beneficial to both in vitro and in vivo FR/NIR fluorescence imaging. The optical properties of the Tat-AIE dots were further studied and compared with commercial Qtracker ${ }^{\circledR} 655$ in water. The $\Phi_{\mathrm{F}}$ of Tat-AIE dots in water is $24 \%$, which is higher than that of Qtracker ${ }^{\circledR} 655$ in water (15\%) measured using 4-(dicyanomethylene)-2-methyl-6-(pdimethylaminostyryl)-4H-pyran in methanol as a standard $\left(\Phi_{\mathrm{F}}=\right.$ $43 \%)^{41}$. The extinction coefficient and absorption cross section at the absorption maximum $(511 \mathrm{~nm})$ for Tat-AIE dots are $8.0 \times 10^{7} \mathrm{M}^{-1}$ $\mathrm{cm}^{-1}$ ( $\sim 26$ fold larger as compared to that of Qtracker ${ }^{\circledR} 655$ at $511 \mathrm{~nm}$ ) and $1.3 \times 10^{-13} \mathrm{~cm}^{2}$ (based on dot concentration as described in the Supplementary Methods), respectively. As the excitation wavelength used in single particle imaging studies is $467 \mathrm{~nm}$, the extinction coefficient of Tat-AIE dots at $467 \mathrm{~nm}$ is also determined to be $5.4 \times 10^{7} \mathrm{M}^{-1} \mathrm{~cm}^{-1}$, which is $\sim 14$ fold larger as compared to that of Qtracker ${ }^{\circledR} 655$ with an average size of $28 \mathrm{~nm}$ in water determined by LLS.

The time-resolved scanning confocal fluorescence microscopy was employed to compare the photophysical properties of Tat-AIE dots and Qtracker ${ }^{\circledR} 655$ as individual dot or in bulk aqueous suspensions. Fluorescence Lifetime Imaging (FLIM) provides spatially resolved fluorescence lifetime data based on the photon arrival statistics at each pixel of the image. When modulated by the total photon counts, FLIM images allow one to identify single nanoobjects by their emission characteristics. Figs $4 \mathrm{a}$ and $4 \mathrm{~b}$ show the FLIM images of Tat-AIE dots and Qtracker ${ }^{\circledR}$ 655, respectively. Each spot in the images corresponds to a single dot. The main differences between FLIM of Tat-AIE dots and Qtracker ${ }^{\circledR} 655$ are the emission intensity, fluorescence lifetime range and the variation of these two parameters between individual dots and during the data acquisition. On average,
Tat-AIE dots are by more than one order of magnitude brighter than Qtracker ${ }^{\circledR} 655$ and display a narrow distribution of fluorescence lifetimes centered around 2-3 ns, while Qtracker ${ }^{\circledR} 655$ clearly shows a broad distribution of lifetimes ranging from several nanoseconds to tens of nanoseconds. Representative fluorescence intensity timetraces (Figs. 4c and 4d) obtained for individual dot (A in Fig. 4a vs $\mathrm{B}$ and $\mathrm{C}$ in Fig. $4 \mathrm{~b}$ ) exemplify the magnitude of the intensity difference and show different emission characteristics of individual TatAIE dot and Qtracker ${ }^{\circledR}$ 655. Comparison between Figs $4 \mathrm{c}$ and $4 \mathrm{~d}$ suggest that the Tat-AIE dot with moderate brightness is $\sim 12-15$ times brighter than Qtracker ${ }^{\circledR}$ 655. Most notably, the notorious intermittent emission, also known as "blinking", of quantum dots ${ }^{23}$, is observed on various time-scales for Qtracker ${ }^{\circledR} 655$ (Fig. 4d), while it is absent for single Tat-AIE dot (Fig. 4c). Solution fluorescence decays for Tat-AIE dots and Qtracker ${ }^{\circledR} 655$ are best fitted with double exponential decay functions and the resulting lifetimes are 2.83 and 13.25 ns (Figs. 4e and 4f), respectively. More importantly, in contrast to Tat-AIE dots, there exists a substantial variation in the fluorescence lifetime for individual Qtracker ${ }^{\circledR} 655$ during data acquisition.

For long-term cell tracing in biological environment, excellent fluorescence stability of the probes is essential. The fluorescence stability of Tat-AIE dots in the cell culture medium (Dulbecco's Modified Eagle Medium, DMEM, supplemented with $10 \%$ fetal bovine serum) was studied first. As shown in Fig. 5a, the fluorescence intensity of Tat-AIE dots remains $93 \%$ of its initial value after 9-day incubation in DMEM at $37^{\circ} \mathrm{C}$. However, Qtracker ${ }^{\circledR} 655$ suffers a sharp drop to $42 \%$ of its initial intensity in 24 hours, which further decreases to $\sim 30 \%$ after 9 days. The photostabilities of Tat-AIE dots and Qtracker ${ }^{\circledR} 655$ in cells were subsequently investigated after a

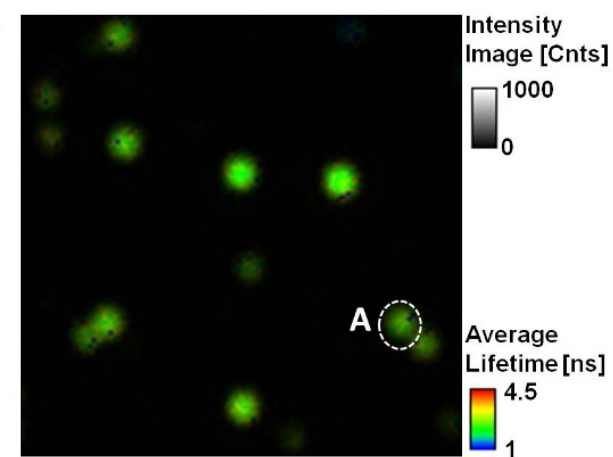

b

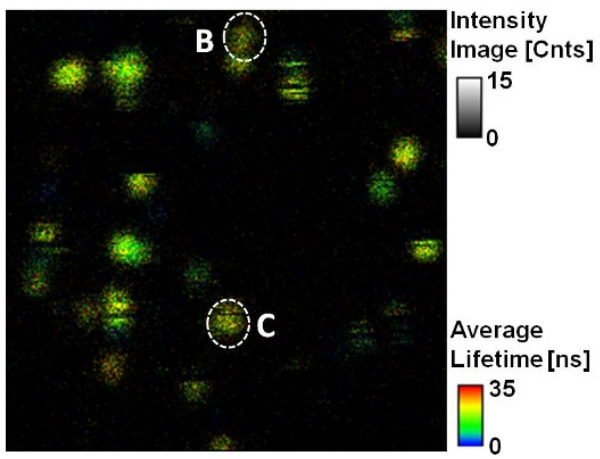

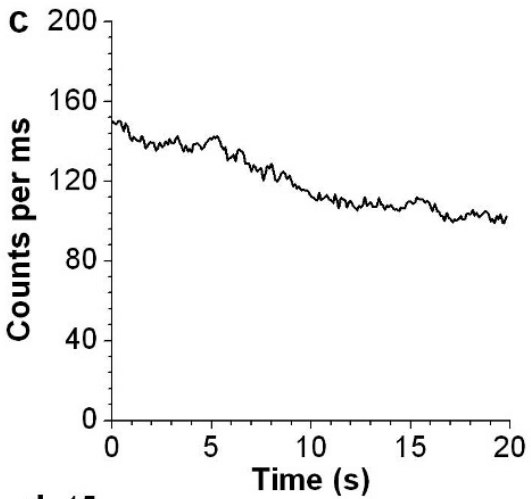

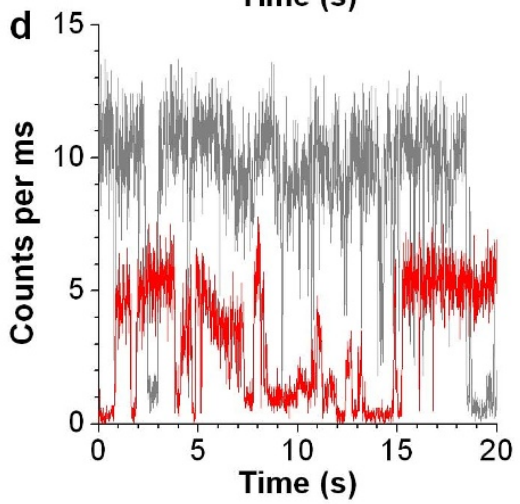

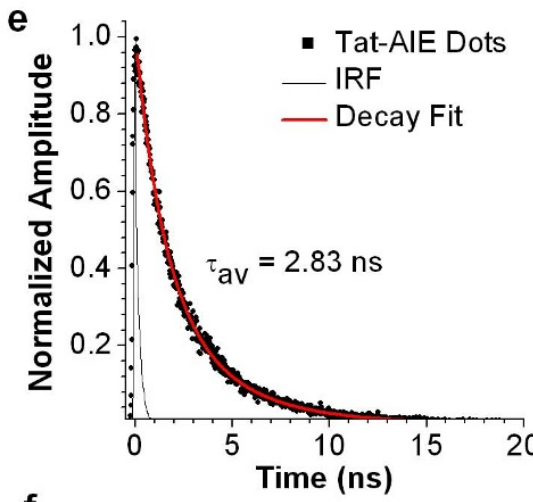

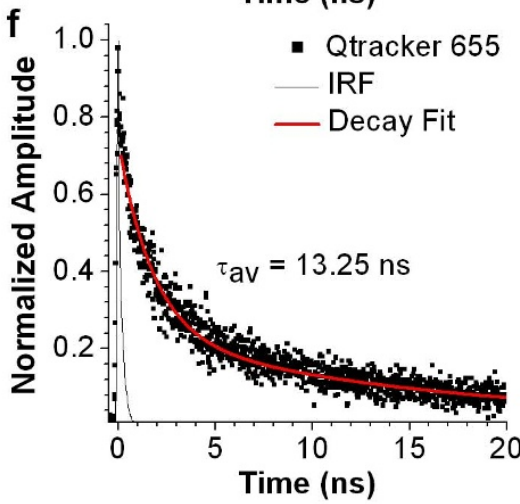

Figure 4 | Comparison of photophysical properties between organic Tat-AIE dots and Qtracker ${ }^{\circledR}$ 655. Fluorescence Lifetime Imaging (FLIM, $5 \times$

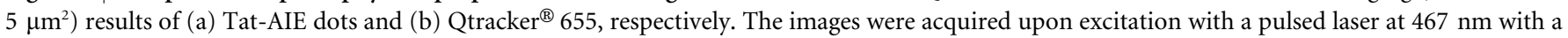
long-pass filter above $505 \mathrm{~nm}$. The image is modulated by the pixel intensity (total photon counts) and the false color scale corresponds to the

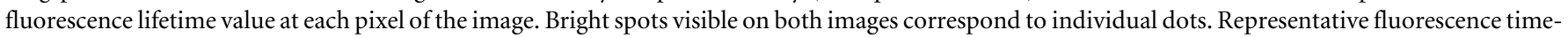

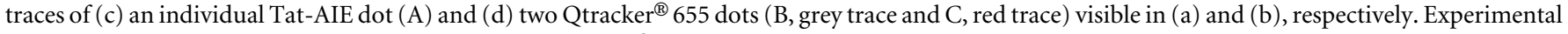

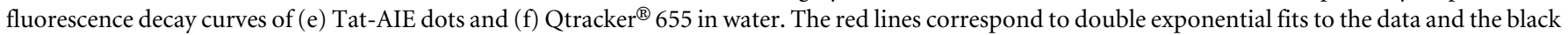
line is the instrument response function. $\tau_{\mathrm{av}}$ is the average fluorescence lifetime calculated from the double exponential decay fits. 
incubation with MCF-7 cancer cells for $4 \mathrm{~h}$ at $37^{\circ} \mathrm{C}$. Upon continuous excitation at $514 \mathrm{~nm}(2 \mathrm{~mW}$, twice of that used in the following in vitro fluorescence imaging) for $10 \mathrm{~min}$, the Tat-AIE dots in cells do not show any obvious change in fluorescence intensity, which is comparable to that of Qtracker ${ }^{\circledR} 655$ (Fig. 5b). Overall, the outstanding stability of Tat-AIE dots will greatly benefit both in vitro and in vivo cell tracing.

In vitro cell tracing. MCF-7 human breast cancer cells were chosen as a model to demonstrate the ability of Tat-AIE dots for in vitro cell tracing application with Qtracker ${ }^{\circledR} 655$ as the reference. The applied Tat-AIE dot and Qtracker ${ }^{\circledR} 655$ concentration is $2 \mathrm{nM}$, which is in the range of recommended working condition for Qtracker ${ }^{\circledR} 655$. The MCF-7 cancer cells were first incubated with Tat-AIE dots and Qtracker ${ }^{\circledR} 655$ for $4 \mathrm{~h}$ at $37^{\circ} \mathrm{C}$, respectively. The labeled cells were then subcultured for designated time intervals and the fluorescence profiles were recorded using flow cytometry by counting 10,000 events $\left(\lambda_{\text {ex }}=488 \mathrm{~nm}, 680 / 20 \mathrm{~nm}\right.$ bandpass filter). Figure $6 \mathrm{a}$ shows that the labeling rate of MCF-7 cells is $99.65 \%$ at the first generation and remains above $95 \%$ at the seventh generation as compared to the untreated cells. The labeling rate is $16.28 \%$ after continuous culture till the tenth generation. On the contrary, only $18.13 \%$ of Qtracker ${ }^{\circledR}$ 655-treated cells are labeled at the fifth generation (Fig. 6b). The results clearly indicate the superior cell tracing ability of Tat-AIE dots over Qtracker ${ }^{\circledR} 655$, which is able to trace 5-6 generations as indicated in the protocol. These results were further confirmed by confocal images. Only very weak fluorescence is detectable in Qtracker ${ }^{\circledR}$ 655-labeled cells while the Tat-AIE dotlabeled cells show high fluorescence signal at the fifth generation (Fig. 6). The fluorescence signal in the confocal images in Fig. 6a is from the Tat-AIE dots since cell autofluorescence is not detectable under the same experimental conditions (Supplementary Fig. S7). The high-resolution fluorescence image indicates that the Tat-AIE dots are internalized into cell cytoplasm and distributed surrounding the nuclei due to their relatively larger size than the nuclear pore (hydrodynamic diameter $\sim 9 \mathrm{~nm})^{42}$ (Supplementary Fig. S8a). As compared to Tat-AIE dots, Qtracker ${ }^{\circledR} 655$ dots are more likely to form nonuniform aggregates in cell cytoplasm (Supplementary Fig. S8b).

To study the retention of Tat-AIE dots in the labeled cells, MCF-7 cells incubated with $2 \mathrm{nM}$ dots for $4 \mathrm{~h}$ were mixed with untreated cells at $1: 1$ ratio and further incubated for 1 day in fresh culture medium. Flow cytometry histogram of the mixture suggests that the ratio of cells with and without fluorescence is almost 1:1 (Fig. 6c), indicating that Tat-AIE dots are hardly to be transferred from the labeled cells to adjacent untreated cells during the co-culture process.
The good intracellular retention of Tat-AIE dots in living cells is ideal in tracing the migration, spread, invasion and morphology change of cancer cells. In addition, when $0.2 \mathrm{nM}$ Tat-AIE dots were incubated with MCF-7 cells, $99.10 \%$ and $10.56 \%$ of the cells were efficiently labeled at the first and seventh generations (Supplementary Fig. S9), respectively, which are comparable to the data obtained using $2 \mathrm{nM}$ Qtracker ${ }^{\circledR} 655$, indicating superior cell tracing ability of the as-prepared Tat-AIE dots. As Qtracker ${ }^{\circledR}$ labeling kits are the most commonly used long-term fluorescent tracing probes, the superior performance of Tat-AIE dots clearly demonstrates their great potentials in practice.

As a critical issue in fluorescence imaging of living biosubstrates, the toxicity of Tat-AIE dots was evaluated through methylthiazolyldiphenyltetrazolium bromide (MTT) assays to determine the metabolic viability of both MCF-7 breast cancer cells and C6 glioma cells after incubation with Tat-AIE dots. The cell viability remains above 95\% after being treated with 1, 2 and $8 \mathrm{nM}$ Tat-AIE dots for $72 \mathrm{~h}$, indicating low cytotoxicity in the test (Supplementary Fig. S10), which is essential for in vitro and in vivo long-term tracing applications.

In vivo cell tracing. For in vivo cell tracing demonstration, $1 \times 10^{6}$ of C6 glioma cells after incubation with $2 \mathrm{nM}$ Tat-AIE dots or Qtracker ${ }^{\circledR} 655$ for 4 h were subcutaneously injected into the flank of the mice, respectively. One-photon excited fluorescence images of treated mice were recorded at $1 \mathrm{~h}$ post injection and thereafter for 21 days using an IVIS ${ }^{\circledR}$ Spectrum Imaging System. As shown in Fig. 7a, intense fluorescence from the injected site can be clearly distinguished at $1 \mathrm{~h}$ post injection (day 0 ). As the cells divide, the whole injected site emits obvious fluorescence signal after 21 days. On the contrary, no fluorescence from the Qtracker ${ }^{\circledR}$ 655-labeled cells can be detected at 7 days post injection (Fig. 7b). Quantitative evaluation of the integrated fluorescence intensity in the region of interest (ROI, marked with blue circles of the same size in Fig. 7) upon injection of Tat-AIE dot-labeled or Qtracker ${ }^{\circledR}$ 655-labeled C6 cells was conducted using IVIS ${ }^{\circledR}$ Spectrum imaging software after substraction of autofluorescence (inset of Fig. 7). The fluorescence intensity $\left(1.08 \times 10^{10}\right)$ of Tat-AIE dot-labeled cells is $\sim 5$-fold higher than that of Qtracker ${ }^{\circledR} 655$-labeled ones $\left(2.05 \times 10^{9}\right)$ upon $1 \mathrm{~h}$ post injection. It is noteworthy that the intensity of Tat-AIE dot-labeled cells after 12 days injection $\left(4.35 \times 10^{9}\right)$ is still twice as high as the initial value of Qtracker ${ }^{\circledR}$ 655-labeled ones. At 21 days post injection, the integrated fluorescence intensity is $4.5 \times 10^{8}$ at the tumor site. These data clearly indicate the great potential of Tat-AIE dots in long-term cell tracing in a living body, which is of high importance in cancer treatment and cell therapy.

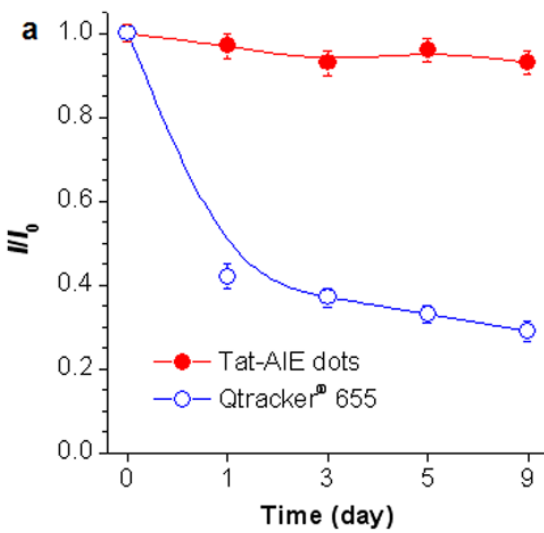

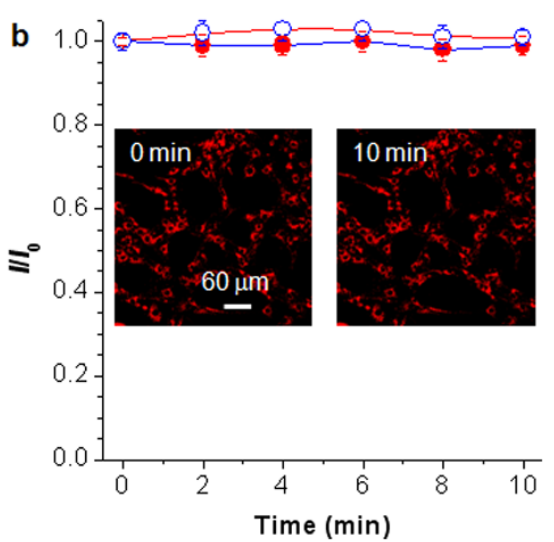

Figure $5 \mid$ Stability of Tat-AIE dots. (a) Time courses of PL intensity change of $2 \mathrm{nM}$ Tat-AIE dots in DMEM with $10 \%$ fetal bovine serum at $37^{\circ} \mathrm{C}$; data for quantum dots of Qtracker ${ }^{\circledR} 655$ are shown for comparison. (b) Photobleaching resistance of Tat-AIE dots and Qtracker ${ }^{\circledR} 655$ to the continuous irradiation by a laser beam $(2 \mathrm{~mW})$ at $514 \mathrm{~nm}$. Insets: confocal images of the Tat-AIE dot-stained cells before $(0 \mathrm{~min})$ and after the laser irradiation for $10 \mathrm{~min} . I_{0}$ is the initial PL intensity, while $I$ is that of the corresponding sample after a designated time interval. 

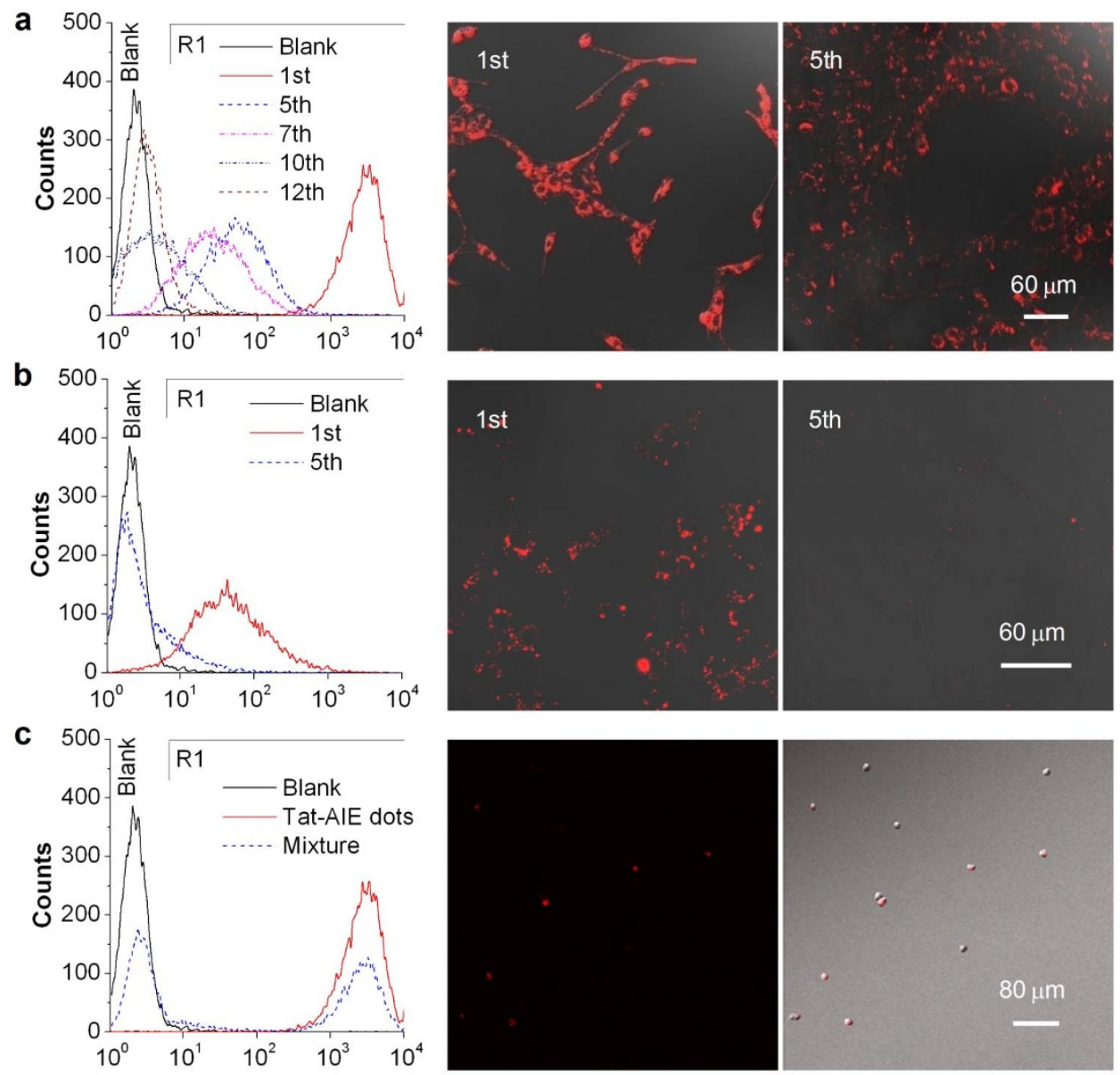

Figure 6 Long-term tracing of living cells by Tat-AIE dots. (a) and (b) Flow cytometry histograms of MCF-7 breast cancer cells after incubation with $2 \mathrm{nM}$ (a) Tat-AIE dots and (b) Qtracker ${ }^{\circledR} 655$ at $37^{\circ} \mathrm{C}$ for $4 \mathrm{~h}$ and then subcultured for designated generations. The untreated MCF-7 cells were used as the control (blank). The corresponding confocal images shown on the right were taken under excitation at $514 \mathrm{~nm}(\sim 1 \mathrm{~mW})$ with a $550-780 \mathrm{~nm}$ bandpass filter. (c) Flow cytometry histograms of the MCF-7 cells stained by $2 \mathrm{nM}$ Tat-AIE dots at $37^{\circ} \mathrm{C}$ for $4 \mathrm{~h}$ (red solid line) and a mixture of Tat-AIE dot-stained MCF-7 cells and unstained cells ( $1: 1$; blue dashed line). The histograms were recorded after subculture for 1 day. The fluorescence image and fluorescence/transmission overlay image of the cell mixture are shown on the right.

Ex vivo one-photon and two-photon excited tumor imaging. Upon 9 days post injection of Tat-AIE dot-labeled C6 glioma cells, one mouse was sacrificed to collect the tumor. The whole tumor was then mounted and imaged upon excitation at $560 \mathrm{~nm}$ using onephoton excited fluorescence microscope. The images were taken layer-by-layer at $3 \mu \mathrm{m}$ interval to monitor the efficient penetration depth of fluoresence from Tat-AIE dots in tumor tissue. As shown in Fig. $8 \mathrm{a}$, the $3 \mathrm{D}$ color-coded projection of deep tissue image reveals that the fluorescence signal can be detected at $220 \mu \mathrm{m}$ depth in the tumor upon excitation at $560 \mathrm{~nm}$. The sectioned tumor image was also obtained, showing clear accumulation of the dots inside cells of the solid tumor (Supplementary Fig. S11).

For tissue imaging, two-photon excited fluorescence technique has advantages over one-photon excited technique in terms of deep penetration depth and low photodamage ${ }^{43}$. It is highly desirable for fluorescent probes to have large two-photon absorption cross sections, which can result in high signal-to-noise ratios in sensitive bioimaging experiments. The maximum two-photon absorption cross-section $(\delta)$ of Tat-AIE dots is $6.7 \times 10^{5} \mathrm{GM}$ (calculated on dot concentration) at $810 \mathrm{~nm}$ using Rhodamine $6 \mathrm{G}$ in methanol as the standard (Supplementary Fig. S12), which gives a two-photon action cross section $\left(\delta \Phi_{\mathrm{F}}\right)$ of $1.6 \times 10^{5} \mathrm{GM}$. The two-photon brightness per unit volume of Tat-AIE dots is estimated to be $12.5 \mathrm{GM}$ $\mathrm{nm}^{-3}$, which is comparable or higher than reported QDs ${ }^{44}$ and other organic nanoaggregates in water ${ }^{45,46}$. With a standard setup (excitation at $800 \mathrm{~nm}$ at $\sim 39 \mathrm{~mW}$ with a $550-780 \mathrm{~nm}$ bandpass filter), the $3 \mathrm{D}$ color-coded projection of two-photon excited fluorescence images of the tumor from 0 to $550 \mu \mathrm{m}$ was obtained (Fig. $8 \mathrm{~b}, \lambda_{\mathrm{ex}}$ $=800 \mathrm{~nm})$. A two-photon image $\left(\lambda_{\text {ex }}=800 \mathrm{~nm}\right)$ for sectioned tumor at $150 \mu \mathrm{m}$ depth is shown as Supplementary Fig. S13. Overall, Tat-AIE dots can act as a promising fluorescent probe for both one-photon and two-photon excited tissue imaging.

\section{Discussion}

The ability to image single-cell migration in real time is important to several research areas such as embryogenesis, cancer metastasis, stem cell therapeutics, and lymphocyte immunology ${ }^{4-6,9}$. In this research area, fluorescence technique has played an important role due to its high sensitivity and temporal resolution. To overcome the shortcomings of inorganic QD-based direct cell labeling reagents, we developed photostable organic fluorescent dots with high quantum yield, bright FR/NIR emission and low cytotoxicity, which could act as a novel class of promising long-term cell tracing probes.

The AIE fluorogens, TPAFN and TPETPAFN, were designed to have high brightness in aggregate states. Bearing two extra TPE units to TPAFN, TPETPAFN has more freely rotated rotors to populate the nonradiative decay channels (e.g., internal conversion) in solution and thus have a more pronounced AIE effect upon nanoparticle 
a

92

90

88

86

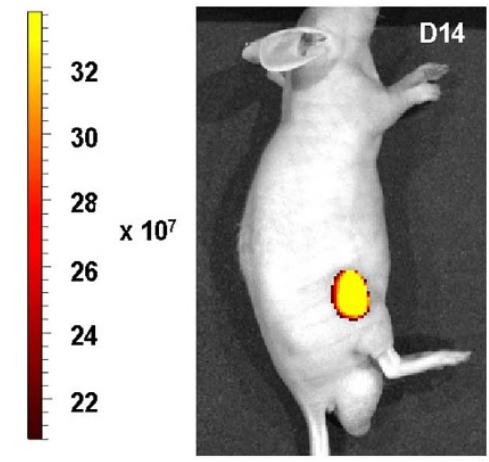

b

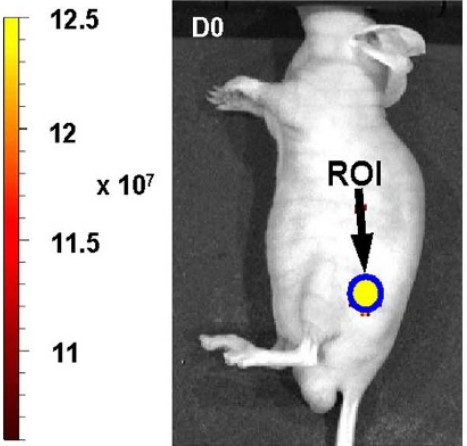

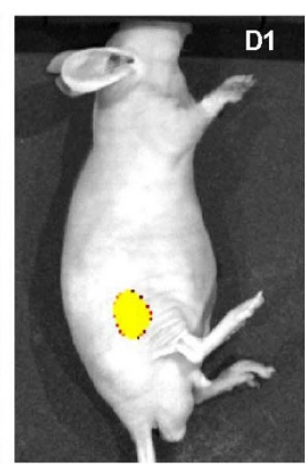
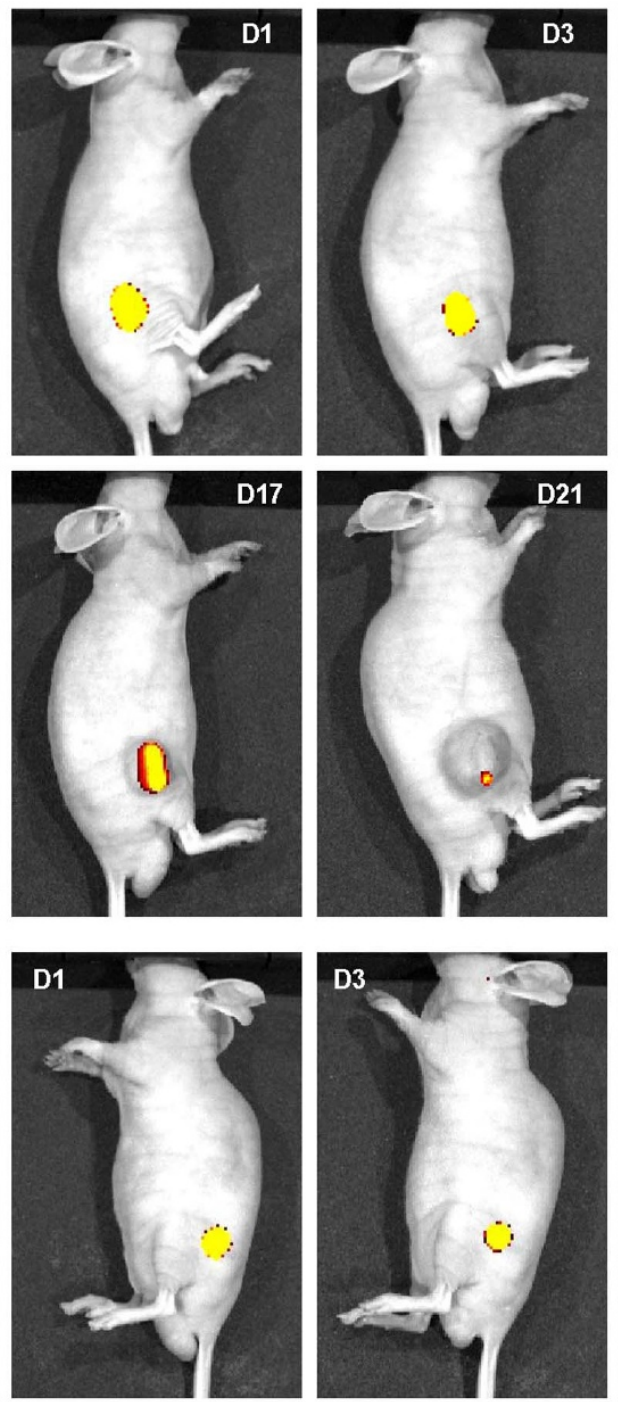

D3
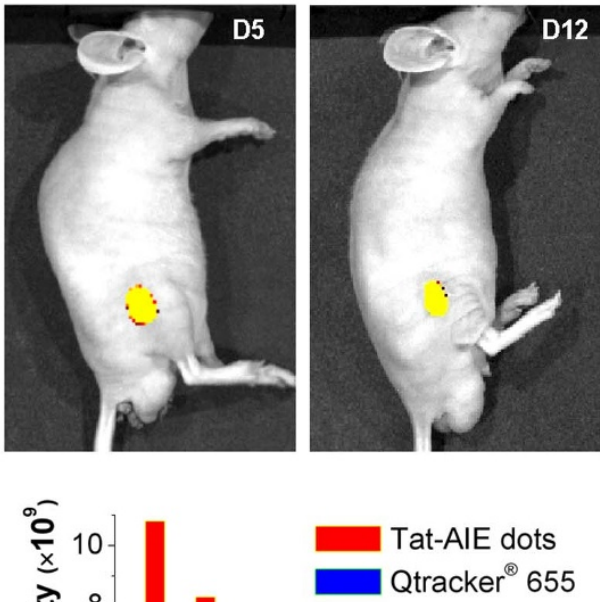
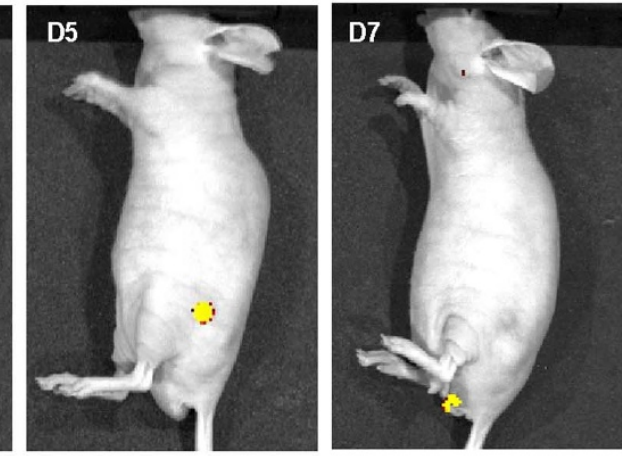

Figure $7 \mid$ In vivo fluorescence imaging of tumor cells by Tat-AIE dots. (a) Representative in vivo fluorescence images of the mouse subcutaneously injected with $1 \times 10^{6}$ of C6 glioma cells after staining by $2 \mathrm{nM}$ Tat-AIE dots. (b) Data for Qtracker ${ }^{\circledR} 655$ obtained under similar conditions. The images were taken on designated days post cell injection. The inset in the middle panel shows the integrated PL intensities of the regions of interest (blue circles) at the tumor sites from the corresponding images.

formation. We further developed a facile and efficient strategy to fabricate TPETPAFN-loaded lipid-PEG-encapsulated AIE dots with surface cell penetrating peptide (HIV-1 Tat) for noninvasive in vitro and in vivo cancer cell tracing. In vitro study suggested that Tat-AIE dots could trace MCF-7 cells up to 12 generations and the internalized dots were efficiently retained inside the cytoplasm to transfer to the daughter cells (Fig. 6). In addition, in vivo study further demonstrated the successful continuous monitoring of Tat-AIE dot-labeled C6 glioma cells in mouse up to 21 days (Fig. 7a). The excellent longterm tracing ability of Tat-AIE dots can be attributed to their stable fluorescene in biological environment (Fig. 5a) and good cellular retention (Fig. 6c). Under the same experimental conditions, the performance of Tat-AIE dots in cell tracing was superior to commercial Qtracker ${ }^{\circledR} 655$ that showed obvious fluorescence decay upon incubation in biological media at $37^{\circ} \mathrm{C}$ (Fig. 5a). Moreover, ex vivo two-photon excited deep tumor imaging with a depth up to $550 \mu \mathrm{m}$ was demonstrated, which was ascribed to the high two-photon absorption cross section and bright FR/NIR fluorescence of the Tat-AIE dots.

This is the first report that organic nanoparticles could be fabricated to show comparable photostability (under imaging conditions) and size, brighter fluorescence, better fluorescence stability and cell tracing ability over commercial QD-based cell tracing probes. More importantly, unlike QD-based probes, the organic fluorescent dots do not blink, and also do not contain heavy metal ions that could be potentially toxic when applied for living systems. These merits make the AIE dots promising alternatives to QDs in fluorescence imaging. As single imaging modality is limited to provide sufficient information in advanced biological studies ${ }^{47-49}$, further efforts will be made to integrate fluorescent AIE dots with versatile imaging modalities (e.g., magnetic resonance and nuclear imaging reagents) to afford multimodal imaging probes with synergistic advantages in terms of high sensitivity, good temporal and spatial resolution.

\section{Methods}

Synthesis of TPETPAFN (9). A mixture of bis(4-bromophenyl)fumaronitrile (2) (194 mg, $0.5 \mathrm{mmol}), N$-(4-(1,2,2-triphenylvinyl)phenyl)benzenamine (7) $(635 \mathrm{mg}$, $1.5 \mathrm{mmol}), \mathrm{Cs}_{2} \mathrm{CO}_{3}(1.14 \mathrm{~g}, 3.5 \mathrm{mmol}), \mathrm{Pd}(\mathrm{OAc})_{2}(11.2 \mathrm{mg}, 0.05 \mathrm{mmol})$, tri-tertbutylphosphine $(30.3 \mathrm{mg}, 0.15 \mathrm{mmol})$ and toluene $(30 \mathrm{~mL})$ was heated at $40^{\circ} \mathrm{C}$ for $2 \mathrm{~h}$. The reaction mixture was then heated at $110^{\circ} \mathrm{C}$ for $24 \mathrm{~h}$. After the mixture was cooled to room temperature, water $(80 \mathrm{~mL})$ and chloroform $(200 \mathrm{~mL})$ were added. The organic layer was separated and washed with brine, dried over anhydrous $\mathrm{MgSO}_{4}$ and evaporated to dryness under reduced pressure. The crude product was purified by column chromatography on silica gel using hexane/toluene $(\mathrm{v} / \mathrm{v}=2 / 1)$ as eluent to afford 9 as a red solid in $61 \%$ yield $(327 \mathrm{mg}){ }^{1} \mathrm{H}$ NMR $\left(300 \mathrm{MHz}, \mathrm{CDCl}_{3}\right), \delta$ (TMS, ppm): $7.66(\mathrm{~d}, J=8.9 \mathrm{~Hz}, 4 \mathrm{H}), 7.31(\mathrm{t}, J=7.9 \mathrm{~Hz}, 4 \mathrm{H}), 7.16-7.02(\mathrm{~m}, 36 \mathrm{H}), 6.98(\mathrm{t}, J$ 
Depth $(\mu \mathrm{m})$

a

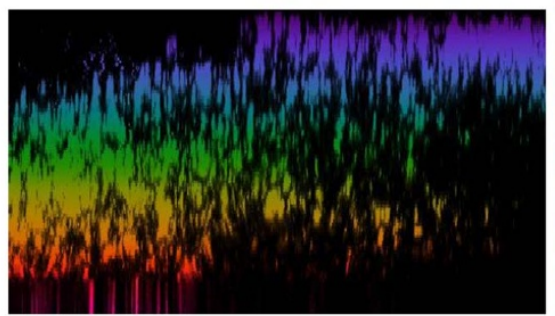

b
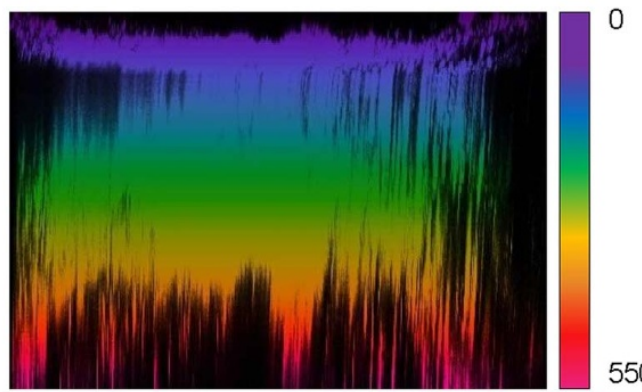

Figure $8 \mid$ Depth profiles of fluorescence images of the tumor stained by Tat-AIE dots. Color-coded projections of z-stacks of (a) one- and (b) twophoton excited fluorescence images indicate the depth of the tumor tissue that can be detected; (a) $\lambda_{\mathrm{ex}}=560 \mathrm{~nm}$, (b) $\lambda_{\mathrm{ex}}=800 \mathrm{~nm}$. The solid tumor was collected from the mouse after 9-day injection of the Tat-AIE dotstained cells. The fluorescence signals were collected with a $550-780 \mathrm{~nm}$ bandpass filter.

$=9.0 \mathrm{~Hz}, 8 \mathrm{H}), 6.87(\mathrm{~d}, J=8.6 \mathrm{~Hz}, 4 \mathrm{H}) ;{ }^{13} \mathrm{C} \mathrm{NMR}\left(75 \mathrm{MHz}, \mathrm{CDCl}_{3}\right), \delta(\mathrm{TMS}, \mathrm{ppm})$ : $150.92,146.83,145.08,144.49,144.19,143.95,141.90,141.05,140.90,133.22,132.01$, $130.49,130.40,130.25,128.34,127.24,126.50,125.46,125.23,121.46,121.22,121.13$, 118.44; HRMS (MALDI-TOF, $\mathrm{m} / \mathrm{z}$ ): $[\mathrm{M}]^{+}$calcd. for $\mathrm{C}_{80} \mathrm{H}_{56} \mathrm{~N}_{4}, 1072.4505$; found, 1072.4502; elemental analysis (calcd., found for $\left.\mathrm{C}_{80} \mathrm{H}_{56} \mathrm{~N}_{4}\right)$ : C $(89.52,89.20), \mathrm{H}(5.26$, $5.23), \mathrm{N}(5.22,5.18)$.

Synthesis of Tat peptide-functionalized AIE dots. A THF solution (1 mL) containing TPETPAFN $(1 \mathrm{mg})$ and a mixture of DSPE-PEG $2000(0.75 \mathrm{mg})$ and DSPE-PEG ${ }_{2000}-\mathrm{NH}_{2}(0.75 \mathrm{mg})$ was poured into water $(9 \mathrm{~mL})$. The mixture was sonicated for 60 seconds using a microtip probe sonicator at $12 \mathrm{~W}$ output (XL2000, Misonix Incorporated, NY). After filtration using a $0.2 \mu \mathrm{m}$ syringe driven filter, the suspension was stirred vigorously at room temperature overnight to yield TPETPAFN-loaded AIE dots in water $(8 \mathrm{~mL})$. The AIE dots $(1.8 \mathrm{~mL})$ were further mixed with borate buffer $(0.2 \mathrm{M}, \mathrm{pH}=8.5,0.6 \mathrm{~mL})$ and reacted with HIV1-Tat peptide $\left(3 \times 10^{-5} \mathrm{M}\right)$ in the presence of EDAC $(1 \mathrm{mM})$. After reaction for $4 \mathrm{~h}$ at room temperature, the solution was dialysed against MilliQ water for 2 days to eliminate the excess peptide and EDAC. The Tat-AIE dots were collected for further use.

Photophysical properties studied by time-resolved scanning confocal fluorescence microscopy. Fluorescence Lifetime Imaging (FLIM) of Tat-AIE dots and Qtracker ${ }^{\circledR}$ 655 was carried out using a MicroTime 200 scanning confocal microscope (Pico Quant, Germany). The samples were excited by a picosecond pulsed laser emitting at $467 \mathrm{~nm}$ and the fluorescence signals were collected using a long-pass filter above $505 \mathrm{~nm}$ (LDH-D-C-470, $15 \mathrm{MHz}$ repetition rate, PicoQuant, Germany) controlled by a PDL 828 Sepia II laser driver. Excitation light was focused on the sample to a diffraction-limited spot using a high NA objective (Olympus, Plan-Apo, 1.4 NA, $100 \times$, oil immersion) mounted in a Olympus IX 71 microscope frame, and the emission was collected from the sample using the same objective and directed through a pinhole onto a Single Photon Avalanche Diode (SPAD, PDM series, Micro Photon Devices, Italy). Instrument response function (IRF) with a full-width at halfmaximum (fwhm) of less than 150 ps was obtained for the lifetime imaging system. The samples for microscopy were prepared by drop-casting diluted nanoparticle solutions onto a glass cover slip (square shaped glass cover slides, $\mathrm{L}=20 \mathrm{~mm}$ ) for few seconds to allow for adhesion of the materials to the glass surface. Excess solution was removed by a pipette. The concentration of the solution was adjusted so that a surface coverage of less than $10 \%$ was obtained, resulting in an average separation well above the optical diffraction limit imposed by the microscope imaging system. All FLIM experiments were performed in air under ambient conditions. FLIM images were obtained by scanning the objective mounted on a piezo scanner across the sample and acquiring the photon arrival statistics at each pixel position using Time-Correlated Single-Photon Counting electronics (PicoHarp 300, PicoQuant, Germany) in the Time-Tagged Time-Resolved mode (TTTR mode). Time-traces of individual dot were obtained by moving the piezo stage to the desired position and focusing the light directly on a single dot.

Fluorescence lifetime decays of Tat-AIE dots and Qtracker ${ }^{\circledR} 655$ solutions were obtained using the same setup configuration but focusing the light $10 \mu \mathrm{m}$ above the glass surface and depositing the solution directly on glass, respectively. To avoid concentration effects, the concentration of the solution was decreased to the level that ensured only one dot in the detection volume at any time. The decays were constructed for all photons detected during 600s. The fluorescence lifetime values were determined by fitting the photon arrival time's histograms with a double exponential decay function.

In vitro cell tracing. MCF-7 breast cancer cells were cultured in 6-well plates (Costar, IL, USA) to achieve $80 \%$ confluence. After medium removal and washing with $1 \times$ PBS buffer, 2 nM Tat-AIE dots or Qtracker ${ }^{\circledR} 655$ in DMEM medium were then added to the wells. After $4 \mathrm{~h}$ incubation at $37^{\circ} \mathrm{C}$, the cells were washed twice with $1 \times \mathrm{PBS}$ buffer and detached by $1 \times$ tripsin and resuspended in culture medium. Upon dilution, the cells were subcultured in 6-well plates containing cell culture coverslips for $1,5,7,10$ and 12 generations, respectively. After designated time intervals, the cells were washed twice with $1 \times$ PBS buffer and then trypsinalized to suspend in $1 \times$ PBS buffer. The fluorescence intensities of cells were then analyzed by flow cytometry measurements using Cyan-LX (DakoCytomation) and the histogram of each sample was obtained by counting 10,000 events $\left(\lambda_{\text {ex }}=488 \mathrm{~nm}, 680 / 20 \mathrm{~nm}\right.$ bandpass filter). To study cell retention of Tat-AIE dots, two groups of cells were used. The sample group was incubated with $2 \mathrm{nM}$ Tat-AIE dots for $4 \mathrm{~h}$ at $37^{\circ} \mathrm{C}$ while the control group remained untreated. After incubation and detachment, $2 \mathrm{~mL}$ of Tat-AIE dot-treated cells and $2 \mathrm{~mL}$ of control cells with the same density $(300,00$ cells $/ \mathrm{mL})$ were mixed and subcultured in culture flasks for 1 day. Meanwhile, the control and sample cells were also subcultured for 1 day. The three batches of cells were then trypsinalized and tested using flow cytometry. In all flow cytometry tests, blank cells without any treatment were used as the control. For confocal image studies, the cells were first labeled by $2 \mathrm{nM}$ Tat-AIE dots or Qtracker ${ }^{\circledR} 655$. The labeled cells were then washed twice with $1 \times$ PBS buffer and detached by $1 \times$ tripsin to resuspend in culture medium. Upon dilution, the cells were subcultured in 6-well plates containing cell culture coverslips for designated generations, washed twice with $1 \times$ PBS buffer and then fixed by $75 \%$ ethanol for 20 minutes. The coverslips were sealed with mounting medium and the fluorescence images were studied by Leica TCS SP 5X. The laser at $514 \mathrm{~nm}(1 \mathrm{~mW})$ was adopted to obtain the one-photon excited fluorescence images with a $550-780 \mathrm{~nm}$ bandpass filter.

Animals. Male SCID mice were obtained from the Biological Resource Centre (Biopolis, Singapore). Mice were housed in groups (5 per cage) and provided with standard mouse chow and water at libitum. The cages were maintained in a room with controlled temperature $\left(25 \pm 1^{\circ} \mathrm{C}\right)$ and a $12 \mathrm{~h} \mathrm{light/dark} \mathrm{cycle} \mathrm{(light} \mathrm{on} \mathrm{at} \mathrm{7:00} \mathrm{am).}$ All animal experiments were performed in compliance with guidelines set by the Institutional Animal Care and Use Committee (IACUC), SingHealth.

In vivo cell tracing. After $4 \mathrm{~h}$ incubation with $2 \mathrm{nM}$ Tat-AIE dots or Qtracker ${ }^{\circledR} 655$ at $37^{\circ} \mathrm{C}$, C6 glioma cells $\left(1 \times 10^{6}\right.$ cells in $0.1 \mathrm{~mL}$ of culture medium $)$ were subcutaneously injected into the flank of mice. Three mice were used for each group. After designated time intervals post injection, the mice were imaged using an IVIS ${ }^{\circledR}$ Spectrum Imaging System (Xenogen Co., Alameda, CA, USA) while under anesthesia using $1-2 \%$ of isoflurane in oxygen. The fluorescence images were recorded with 1 second exposure using a filter $660 / 20 \mathrm{~nm}$ upon excitation at $535 \mathrm{~nm}$. Scans were carried out on $0 \mathrm{~d}(1 \mathrm{~h}), 1 \mathrm{~d}, 3 \mathrm{~d}, 5 \mathrm{~d}, 7 \mathrm{~d}, 12 \mathrm{~d}, 14 \mathrm{~d}, 17 \mathrm{~d}$ and $21 \mathrm{~d}$. The autofluorescence was removed using the software of IVIS ${ }^{\circledR}$ Spectrum Imaging System.

1. Ly, H. Q., Frangioni, J. V. \& Hajjar, R. J. Imaging in cardiac cell-based therapy: in vivo tracking of the biological fate of therapeutic cells. Nat. Clin. Pract. Cardiovasc. Med. 5, S96-S102 (2008).

2. Amado, L. C. et al. Cardiac repair with intramyocardial injection of allogeneic mesenchymal stem cells after myocardial infarction. Proc. Natl. Acad. Sci. USA 102, 11474-11479 (2005)

3. Schächinger, V. et al. Transplantation of progenitor cells and regeneration enhancement in acute myocardial infarction: Final one-year results of the TOPCARE-AMI Trial. J. Am. Coll. Cardiol. 44, 1690-1699 (2004).

4. Ebert, S. N. et al. Noninvasive tracking of cardiac embryonic stem cells in vivo using magnetic resonance imaging techniques. Stem Cells 25, 2936-2944 (2007)

5. Doubrovin, M. M. et al. In vivo imaging and quantitation of adoptively transferred human antigen-specific $\mathrm{T}$ cells transduced to express a human norepinephrine transporter gene.Cancer Res. 67, 11959-11969 (2007).

6. Ottobrini, L., Martelli, C., Trabattoni, D. L., Clerici, M. \& Lucignani, G. In vivo imaging of immune cell trafficking in cancer. Eur. J. Nucl. Med. Mol. Imaging 38, 949-968 (2011).

7. Adonai, N. et al. Ex vivo cell labeling with ${ }^{64} \mathrm{Cu}$-pyruvaldehyde-bis(N4methylthiosemicarbazone) for imaging cell trafficking in mice with positronemission tomography. Proc Natl. Acad. Sci. USA 99, 3030-3035 (2002).

8. Kraitchman, D. L. et al. Dynamic imaging of allogeneic mesenchymal stem cells trafficking to myocardial infarction. Circulation 112, 1451-1461 (2005).

9. Zhang, F. et al. In vivo MRI tracking of cell invasion and migration in a rat glioma model. Mol. Imag. Biol. 13, 695-701 (2011). 
10. Kondepati, V. R., Heise, H. M. \& Backhaus, J. Recent applications of near-infrared spectroscopy in cancer diagnosis and therapy. J. Anal. Bioanal. Chem. 390, 125-139 (2008).

11. Kircher, M. F., Gambhir, S. S. \& Grimm J. Noninvasive cell-tracking methods. Nat. Rev. Clinic. Oncol. 8, 677-688 (2011).

12. Wang, S. \& Hazelrigg, T. Implications for $b c d$ mRNA localization from spatial distribution of exu protein in Drosophila oogenesis. Nature 369, 400-403 (1994).

13. Daly, C. J. \& McGrath, J. C. Fluorescent ligands, antibodies, and proteins for the study of receptors. Pharmacol. Ther. 100, 101-118 (2003).

14. Jaiswal, J. K., Goldman, E. R., Mattoussi, H. \& Simon, S. M. Use of quantum dots for live cell imaging. Nat. Methods 1, 73-78 (2004).

15. Gao, X. H., Cui, Y. Y., Levenson, R. M., Chuang, L. W. K. \& Nie, S. M. In vivo cancer targeting and imaging with semiconductor quantum dots. Nat. Biotechnol. 22, 969-976 (2004).

16. Shah, B. S. et al. Labeling of mesencheymal stem cells by bioconjugated quantum dots. Nano Lett. 7, 3071-3079 (2007).

17. Dellambra, E. et al. Toward epidermal stem cell-mediated ex vivo gene therapy of junctional epidermolysis bullosa. Hum. Gene Ther. 11, 2283-2287 (2000).

18. Lin, S. et al. Quantum dot imaging for embryonic stem cells. BMC Biotechnol. 7, 67-76 (2007).

19. Muller-Borer, B. J., Collins, M. C., Gunst, P. R., Cascio, W. E. \& Kypson, A. P. Quantum dot labeling of mesenchymal stem cells. J. Nanobiotechnol. 5, 9 (2007).

20. Xin, L., Lukacs, R. U., Lawson, D. A., Cheng, D. \& Witte, O. N. Self-renewal and multilineage differentiation in vitro from murine prostate stem cells. Stem Cells 25, 2760-2769 (2007).

21. Fotos, J. S. et al. Automated time-lapse microscopy and high-resolution tracking of cell migration. Cytotechnol. 51, 7-19 (2006).

22. Yang, K., Li, Z., Cao, Y., Yu, X. \& Mei J. Effect of peptide-conjugated near-infrared fluorescent quantum dots (NIRF-QDs) on the invasion and metastasis of human tongue squamous cell carcinoma cell line Tca8113 in vitro. Int. J. Mol. Sci. 10, 4418-4427 (2009).

23. Smith, A. M., Duan, H., Mohs, A. M. \& Nie, S. M. Bioconjugated quantum dots for in vivo molecular and cellular imaging. Adv. Drug. Deliv. Rev. 60, 1226-1240 (2008).

24. Alford, R. et al. Toxicity of organic fluorophores used in molecular imaging: literature review. Mol. Imag. 8, 341-354 (2009).

25. Marks, K. M. \& Nolan, G. P. Chemical labeling strategies for cell biology. Nat. Methods 3, 591-596 (2006).

26. Chithrani, B. D. \& Chan, W. C. Elucidating the mechanism of cellular uptake and removal of protein-coated gold nanoparticles of different sizes and shapes. Nano Lett. 7, 1542-1550 (2007).

27. Dombu, C. Y., Kroubi, C. Y. M., Zibouche, R., Matran, R. \& Betbeder, D. Characterization of endocytosis and exocytosis of cationic nanoparticles in airway epithelium cells. Nanotechnology 21, 355102 (2010).

28. Birks, J. B. Photophysics of Aromatic Molecules. Wiley-Interscience, London (1970).

29. Hong, Y., Lam, J. W. Y. \& Tang, B. Z. Aggregation-induced emission. Chem. Soc. Rev. 40, 5361-5388 (2011).

30. Hong, Y., Lam, J. W. Y. \& Hong, Y., Lam, J. W. Y. \& Tang, B. Z. Aggregationinduced emission: phenomenon, mechanism and applications. Chem. Commun. 4332-4353 (2009).

31. Kim, S., Pudavar, H. E., Bonoiu, A. \& Prasad, P. N. Aggregation-enhanced fluorescence in organically modified silica nanoparticles: a novel approach toward high-signal-output nanoprobes for two-photon fluorescence bioimaging. $A d v$. Mater. 19, 3791-3795 (2007).

32. Velusamy, M. et al. A new series of quadrupolar type two-photon absorption chromophores bearing 11,12-dibutoxydibenzo[a,c]-phenazine bridged amines; their applications in two-photon fluorescence imaging and two-photon photodynamic therapy. Adv. Funct. Mater. 19, 2388-2397 (2009).

33. Wang, D. et al. Aggregation-enhanced fluorescence in PEGylated phospholipid nanomicelles for in vivo imaging. Biomaterials 32, 5880-5888 (2011).

34. Yu, Y. et al. Cytophilic fluorescent bioprobes for long-term cell tracking. Adv. Mater. 23, 3298-3302 (2011).

35. Ding, D. et al. Conjugated polyelectrolyte-cisplatin complex nanoparticles for simultaneous in vivo imaging and drug tracking. Nanoscale 3, 1997-2002 (2011).

36. Kaplan, I. M., Wadia, J. S. \& Dowdy, S. F. Cationic Tat peptide transduction domain enter cells by macropinocytosis. J. Control. Release 102, 247-253 (2005).
37. Zhao, Q. et al. Tetraphenylethenyl-modified perylene bisimide: aggregationinduced red emission, electrochemical property and ordered microstructures. J. Mater. Chem. 22, 7387-7394 (2012)

38. Qin, W. et al. Biocompatible nanoparticles with aggregation-induced emission characteristics as far-red/near-infrared fluorescent bioprobes for in vitro and in vivo imaging application. Adv. Funct. Mater. 22, 771-779 (2012).

39. Li, K. et al. Folic acid-functionalized two-photon absorbing nanoparticles for targeted MCF-7 cancer cell imaging. Chem. Commun. 47, 7323-7325 (2011).

40. Piantavigna, S. et al. A mechanistic investigation of cell-penetrating Tat peptides with supported lipid membranes. Biochim. Biophys. Acta 1808, 1811-1817 (2011).

41. Drake, J. M., Lesiecki, M. L. \& Camaioni, D. M. Photophysics and cis-trans isomerization of DCM. Chem. Phys. Lett. 113, 530-534 (1985).

42. Keminer, Q. \& Peter, R. Permeability of single nuclear pores. Biophys. J. 77, 217-228 (1999)

43. Helmchen, F. \& Denk, W. Deeper tissue two-photon microscopy. Nat. Methods 2, 932-940 (2005)

44. Larson, D. R. et al. Water-soluble quantum dots for multiphoton fluorescence imaging in vivo. Science 300, 1434-1436 (2003).

45. Ishow, E. et al. Multicolor emission of small molecule-based amorphous thin films and nanoparticles with a single excitation wavelength. Chem. Mater. 20, 6597-6599 (2008).

46. Parthasarathy, V. et al. Dipolar versus octupolar triphenylamine-based fluorescent organic nanoparticles as brilliant one- and two-photon emitters for (bio)imaging. Small 7, 3219-3229 (2011).

47. Jin, Y., Jia, C., Huang, S.-W., O’Donnell, M. \& Gao, X. Multifunctional nanoparticles as coupled contrast agents. Nat. Commun. 1, 41 (2010).

48. Li, K. et al. Conjugated polymer based nanoparticles as dual-modal probes for targeted in vivo fluorescence and magnetic resonance imaging. Adv. Func. Mater. 22, 3107-3115 (2012).

49. Bhirde, A., Xie, J., Bhirde, A., Xie, J., Swierczewska, M. \& Chen, X. Nanoparticles for cell labeling. Nanoscale 3, 142-153 (2011).

\section{Acknowledgments}

We are grateful to the support from the Institute of Materials Research and Engineering of Singapore (IMRE/11-1C0213), the Singapore National Research Foundation

(R-279-000-323-281), the Research Grants Council of Hong Kong (603509, HKUST2/CRF/ 10, 604711 and N_HKUST620/11), the University Grants Committee of Hong Kong (AoE/ P-03/08), HKUST (RPC11SC09 and SRF11SC03PG), the National Science Foundation of China (20974028) and partial support by the Guangdong Innovative Research Team Program (201101C0105067115). We thank Professor Kam Sing Wong in Department of Physics in HKUST for the measurement of fluorescence quantum yields of solid powder samples, Ms. Tong Yan in confocal microscopy lab from Centre for BioImaging Sciences (CBIS) in NUS for technical support in confocal imaging experiments.

\section{Author contributions}

K.L., W.Q., B.L. and B.Z.T. designed the research. K.L., W.Q., D.D., N.T., J.G., R.L., N.T., X.Z. and H.L. carried out the experiments. K.L., W.Q., D.D., J.G., J.L., B.L. and B.Z.T. analysed data and participitated in the discussion. K.L., W.Q., J.L., N.T., B.L. and B.Z.T. wrote and revised the paper. All authors reviewed the manuscript.

\section{Additional information}

Supplementary information accompanies this paper at http://www.nature.com/ scientificreports

Competing financial interests: The authors declare no competing financial interests.

License: This work is licensed under a Creative Commons

Attribution-NonCommercial-NoDerivativs 3.0 Unported License. To view a copy of this license, visit http://creativecommons.org/licenses/by-nc-nd/3.0/

How to cite this article: Li, K. et al. Photostable fluorescent organic dots with aggregation-induced emission (AIE dots) for noninvasive long-term cell tracing. Sci. Rep. 3, 1150; DOI:10.1038/srep01150 (2013). 